Abstracta Iranica

Revue bibliographique pour le domaine irano-aryen

Volume 40-41 | 2019

Comptes rendus des publications de 2017-2018

\title{
Damien Agut-Labordere. « Prélèvement et redistribution du blé à 'Ayn Manâwir »
}

\section{Rémy Boucharlat}

\section{(2) OpenEdition}

1 Journals

\section{Édition électronique}

URL : http://journals.openedition.org/abstractairanica/48149

DOI : 10.4000/abstractairanica.48149

ISBN : 1961-960X

ISSN : 1961-960X

Éditeur :

CNRS (UMR 7528 Mondes iraniens et indiens), Éditions de l'IFRI

Référence électronique

Rémy Boucharlat, « Damien Agut-Labordere. "Prélèvement et redistribution du blé à 'Ayn Manâwir » », Abstracta Iranica [En ligne], Volume 40-41 | 2019, document 8, mis en ligne le 15 juillet 2019, consulté le 21 avril 2021. URL : http://journals.openedition.org/abstractairanica/48149; DOI : https://doi.org/ 10.4000/abstractairanica.48149

Ce document a été généré automatiquement le 21 avril 2021.

Tous droits réservés 


\title{
Damien Agut-Labordere. «Prélèvement et redistribution du blé à 'Ayn Manâwir »
}

\author{
Rémy Boucharlat
}

\section{RÉFÉRENCE}

Damien Agut-Labordere. « Prélèvement et redistribution du blé à 'Ayn Manâwir » dans Adeline Bats (éd.). Les céréales dans le monde antique. Regards croisés sur les stratégies de gestion des cultures, de leur stockage et de leurs modes de consommation. Actes du colloque les céréales dans le monde antique, organisé par Pierre Tallet et Adeline Bats, Université ParisSorbonne, 5-6 novembre 2015, NeHeT 5 (2017), p. 71-79

1 L'A présente un petit dossier de sept ostraca écrits en démotique entre la dernière année d'Artaxerxès I et la $9^{e}$ année de Darius II concernant 4 reçus et 3 ordres de livraison d'orge à Ayn Manâwir dans l'oasis de Kharga en Haute Egypte. Les produits agricoles représentent presque la moitié des centaines d'ostraca trouvés sur le site, mais les céréales y sont moins importantes que le ricin, malgré l'un des reçus concernant 4 à 5 tonnes de grain.

2 Le personnage en charge de ces opérations semble n'être qu'un intermédiaire qui, issu du village, jouit de la confiance des fermiers. Il est peut-être aussi chargé du stockage des grains, mais les silos qui correspondraient n'ont pas été trouvés en fouille. Ce mode de fonctionnement des prélèvements pour le temple se poursuivra largement à l'époque ptolémaïque. 


\section{AUTEURS}

\section{RÉMY BOUCHARLAT}

UMR 5133 CNRS-Université de Lyon 